University of Pennsylvania Carey Law School

Penn Law: Legal Scholarship Repository

Faculty Scholarship at Penn Law

6-2007

\title{
Medical Malpractice Reform and Physicians in High-Risk Specialties
}

Jonathan Klick

University of Pennsylvania Carey Law School

Thomas Stratmann

George Mason University

Follow this and additional works at: https://scholarship.law.upenn.edu/faculty_scholarship

Part of the Health Economics Commons, Health Law and Policy Commons, Health Policy Commons, Law and Economics Commons, Law and Society Commons, Litigation Commons, Medicine and Health Commons, and the Torts Commons

\section{Repository Citation}

Klick, Jonathan and Stratmann, Thomas, "Medical Malpractice Reform and Physicians in High-Risk Specialties" (2007). Faculty Scholarship at Penn Law. 1117. https://scholarship.law.upenn.edu/faculty_scholarship/1117

This Article is brought to you for free and open access by Penn Law: Legal Scholarship Repository. It has been accepted for inclusion in Faculty Scholarship at Penn Law by an authorized administrator of Penn Law: Legal Scholarship Repository. For more information, please contact PennlawIR@law.upenn.edu. 


\title{
Medical Malpractice Reform and Physicians in High-Risk Specialties
}

\author{
Jonathan Klick and Thomas Stratmann
}

\begin{abstract}
If medical malpractice reform affects the supply of physicians, the effects will be concentrated in specialties facing high liability exposure. Many doctors are likely to be indifferent regarding reform, because their likelihood of being sued is low. This difference can be exploited to isolate the causal effect of medical malpractice reform on the supply of doctors in high-risk specialties, by using doctors in low-risk specialties as a contemporaneous within-state control group. Using this triple-differences design to control for unobserved effects that correlate with the passage of medical malpractice reform, we show that only caps on noneconomic damages have a statistically significant effect on the per capita number of doctors and that this effect is concentrated among only those specialties that face the highest litigation exposure.
\end{abstract}

\section{INTRODUCTION}

The American Medical Association (AMA) and other supporters of medical malpractice reform assert that, in the face of rising liability premiums, many doctors are forced to cut back on the services that they offer, retire before they had planned, or move to states that enact tort reform. Opponents of reform, however, point to studies suggesting that there is little correlation between liability payments and premiums to debunk the reformers' claims. They also note that studies of doctors' location decisions imply that the effect of medical malpractice reform

JOnathan KLICK is the Jeffrey A. Stoops Professor of Law at Florida State University. thomas stratmann is Professor of Economics at George Mason University. We thank Mark Duggan, Bill Evans, Jonah Gelbach, Eric Helland, and Anup Malani for helpful comments on this paper. 
on physicians' location decisions is modest at best (see, for example, Baker 2005, ch. 7).

In this paper, we revisit the physician location issue and argue that existing studies do not fully exploit the available experiment offered by state reforms. Specifically, because only the subset of physicians practicing in high-risk specialties are likely to be affected by a medical malpractice crisis, physicians in low-risk specialties represent a contemporaneous within-state comparison group. By exploiting this control group, we can net out unobservable effects that correlate with medical malpractice reforms but that are not adequately captured by time-invariant state fixed effects or generic year effects. Most significant, existing studies have had difficulty ruling out the possibility that medical malpractice reforms are endogenous to forces that correlate with physician supply, such as the political clout of doctors as a group or state preferences for medical services. To the extent that these forces are correlated with the total supply of doctors in a state and not just the subset of physicians in high-risk specialties, using physicians in low-risk specialties as a control group will mitigate the potential for simultaneity bias.

Employing a triple-differences identification strategy in which physicians in high-liability specialties in states that pass medical malpractice reform serve as the treatment group and physicians in low-liability specialties in those same states serve as the contemporaneous control group, we find that only caps on noneconomic damages have a large and statistically significant effect on doctors' location decisions and that the effect is concentrated entirely in those specialties that face the most exposure to medical malpractice liability.

These results suggest that medical malpractice reform can generate large increases in the supply of medical services in a state. However, not all the commonly proposed reforms are justified on this basis, and the effects appear to be limited to only a subset of physicians. Thus, it may make sense to focus reform efforts on noneconomic damage caps and to tailor them to apply only to certain specialties. Our paper represents the only attempt in the literature to distinguish the effects of different kinds of medical malpractice reforms.

In Section 2 of this paper, we review the existing evidence on the relationship between medical malpractice reform and physician location. We then describe our identification strategy and the data that we examined in Section 3, while presenting results in Section 4. Section 5 discusses the policy implications of our results, and the conclusion follows in Section 6. 


\section{PREVIOUS STUDIES OF REFORM AND PHYSICIAN SUPPLY}

Klick and Stratmann (2005) was the first study to examine the effects of individual reforms on the labor supply of physicians. In that paper, we found that the only reforms with consistent statistically significant effects on doctors' location decisions are caps on noneconomic damages and the establishment of victims' funds. We also found that caps lead to a 2 percent increase in the number of doctors per capita, whereas victims' funds lead to a decline in the number of doctors of almost 4 percent. In an attempt to control for the endogeneity of reform, we implemented an instrumental variables technique, finding that only the effect of noneconomic damage caps survived after controlling for endogeneity.

Kessler, Sage, and Becker (2005) collapsed medical malpractice reforms into two categories: direct (reforms that directly affect how much a defendant will have to pay in the event of a judgment) and indirect (limitations on whom/when a plaintiff can sue). In a difference-indifference regression framework, they found that direct reforms increase physician supply by about 3 percent and that the effect is concentrated among physicians in high-risk specialties.

Encinosa and Hellinger (2005) used county-level data to examine the effect of caps on noneconomic damage awards on physician supply. They found that adoption of caps leads to an increase in physician supply of 2 percent in general and of more than 3 percent in rural counties. In a longer time series, Matsa (2007) also examined the effect of damage caps on county physician labor supply and found that caps increase the supply of specialists in rural areas by more than 10 percent. These results are basically consistent with those of Baicker and Chandra (2004), who found that increases in liability costs lead to statistically significant reductions in the supply of physicians in rural counties.

Dranove and Gron (2005) examined the labor supply of individual physicians in Florida and found that neurosurgeons significantly cut back the volume of brain surgeries that they perform when medical malpractice premiums rise. They found no similar effect for obstetricians. This somewhat conflicts with the indirect results on physician supply described by Dubay, Kaestner, and Waidmann (2001), who found that expectant mothers have greater access to prenatal care when liability exposure is low.

Helland and Showalter (2006), using an approach similar to the one we implement here, examined the intensive margin of physician labor 
supply. They found that damage caps induce physicians to work more hours in a year, and the effect is statistically significant. In addition, similar to our results, they found that the effect is most pronounced in those specialties facing the most liability exposure.

Taking a different approach, Mello et al. (2004) surveyed specialists in Pennsylvania and found that their professional satisfaction is negatively related to liability exposure. This is consistent with their later results (Mello et al. 2005) that suggest that Pennsylvania specialists have scaled back their practices and are more likely to retire early as a result of liability exposure. Their results also indicate that this has led to a reduction in access to care for patients in Pennsylvania.

Although most of these studies point in a similar direction (that is, at least some medical malpractice reforms increase physician supply in at least some underserved communities), all suffer from potential endogeneity, with the exception of Helland and Showalter (2006). That is, if states tend to pass reforms when doctors are particularly numerous (and, therefore, politically powerful) or when state residents have a particularly high demand for medical services, the positive relationship between reform and physician supply is biased upward. Although Klick and Stratmann (2005) made some improvements in this direction by using instrumental variables analysis, it is difficult to find strong instruments for multiple reforms, especially when reforms tend to be passed in packages. ${ }^{1}$ Thus, the existing literature provides relatively little confidence in the causal effect of reforms on physician supply. ${ }^{2}$

\section{DATA AND IDENTIFICATION STRATEGY}

We examine physician location using AMA data on the number of doctors in each specialty in each state for the years 1980-2001. ${ }^{3}$ To define

1. In Klick and Stratmann (2005), our approach endogenized some reforms (that is, those that appear to be important in ordinary least squares regressions) through instrumental variables techniques, while including the other reforms as endogenous regressors. However, if the other reforms are important in determining physician location, as well as being endogenous and correlated with the instrumented reforms, omitting them or including them directly in the regression will bias the estimated effects of the instrumented reforms.

2. Another possible form of simultaneity arises if states pass reforms only when they are in a crisis because doctors have exited the state. If this is the case, estimated coefficients will be biased toward zero.

3. American Medical Association, AMA Physician Masterfile (American Medical Association, 515 North State Street, Chicago, IL 60610). Data are not available for 1984 and 1990 , so those years are omitted from our data set. 
our treatment and comparison groups, using the Florida Closed Claims Medical Malpractice data set, ${ }^{4}$ we identify the 10 specialties exhibiting the highest average medical malpractice awards per doctor and the 10 specialties with the lowest average awards. ${ }^{5}$ Our dependent variable is the natural $\log$ of the number of doctors in each of these specialties in each state per 100,000 state residents. ${ }^{6}$

For physicians in low-risk specialties to serve as an adequate control, this group must satisfy two criteria. First, the unobservable factors driving physicians' location decisions within each of these groups must be highly correlated. If this is not the case, the control group does nothing to mitigate the endogeneity concerns described above. Second, the location decisions of physicians in low-risk specialties must be mostly unaffected by medical malpractice reforms.

With regard to the first criterion, we provide evidence in Table A1 that the number of physicians in low-risk specialties per capita is a positive predictor of the number of physicians in high-risk specialties per capita in three separate specifications: specification (1) controls for just a constant and the low-risk-specialty variable, specification (2) adds state and year fixed effects to specification (1), and specification (3) adds state-specific linear trends to specification (2). In each case, with robust or state-clustered standard errors, the effects are highly statistically significant, generating $p$-values less than .0005 . Further, this single predictor explains a large portion of the variation in the number of physicians in high-risk specialties per capita, generating an $R^{2}$-value of .761 in specification (1).

The assumption that physicians in low-risk specialties are unaffected by medical malpractice reforms would likely be proved false if insurers pool risk for physicians in high- and low-risk specialties. If this is the case, our estimates of the effects of medical malpractice reforms on the

4. Florida Medical Malpractice Closed Claims (Florida Department of Financial Services, 200 East Gaines Street, Tallahassee, FL 32399). See Helland, Klick, and Tabarrok (2005) for a description of this data set.

5. Specialties with the most claims awarded are (in decreasing order) neurological surgery, thoracic surgery, obstetrics and gynecology, general practice, emergency room, plastic surgery, radiology, anesthesiology, general surgery, and cardiovascular disease. Specialties with the fewest claims awarded are (in increasing order) diabetes, neoplastic diseases, oncology, public health, psychiatry, allergy, rheumatology, physical medicine, dermatology, and nephrology.

6. Use of the natural log to remove the scale effects in the data is potentially important given the fairly large differences in the number of doctors in each specialty. If we instead use the level as our dependent variable, the results in terms of sign and statistical significance are mostly unchanged, although the magnitudes of the treatment effects differ. 
location decisions of physicians in high-risk specialties will be biased toward zero. However, this possibility seems remote for the specific specialties in our control group. Since the physicians in these specialties are very rarely sued, any attempt to pool their risk with that of physicians in specialties exposed to medium to high litigation risk should induce separation, since physicians in these low-risk specialties either drop coverage or seek insurers covering only physicians in low-risk specialties. ${ }^{7}$

We examine the effects of those reforms that constitute the AMA's legislative priorities: ${ }^{8}$ caps on noneconomic damages, collateral source reform, joint and several liability reform, caps on attorney contingency fees, and mandatory periodic payment of future damages. We also include caps on total medical malpractice damages and the creation of no-fault victims' compensation funds, since these reforms have been identified by other groups as being particularly important for the specialties of primary interest, especially obstetrics. Data for these reforms come from the American Tort Reform Association. ${ }^{9}$

Although most existing studies do not examine reforms separately or focus on only noneconomic damage caps, this approach has the potential to lead to omitted variable biases. Specifically, since reforms tend to be passed in packages, the passage of noneconomic damage caps is correlated with the passage of other reforms. If the other reforms affect physicians' location decisions, the estimated effect of noneconomic damage caps will be biased. Further, the Kessler, Sage, and Becker (2005) approach of grouping reforms as direct and indirect is potentially problematic if some reforms have a negative effect on doctors' location decisions. ${ }^{10}$ Summary statistics are presented in Table 1.

For comparison purposes, we present the results of a simple difference-in-difference model of the effect of tort reforms on physicians in

7. For example, the American Psychiatric Association endorses an insurance plan that restricts coverage to psychiatrists only (see The Psychiatrists' Program, Professional Liability Insurance Designed for Psychiatrists [http://www.psychprogram.com/psychpro.htm]). Psychiatrists have the fifth lowest liability exposure by our measure.

8. These reforms are identified at American Medical Association, AMA Agenda: Advocacy Efforts (http://www.ama-assn.org/ama/pub/category/7861.html).

9. American Tort Reform Association, Medical Liability Reform (http://www.atra .org/issues/index.php? issue $=7338$ ).

10. In theory, joint and several liability reform could lead to a negative effect on doctors' location decisions if doctors favor the partial liability shield offered by joint and several liability as plaintiffs go after the deeper pockets of hospitals or other doctors. Also, no-fault victims' funds could generate this effect because they are funded by a tax on doctors. Klick and Stratmann (2005) found some evidence of the negative effects of these reforms, although the effects are not uniformly statistically significant. 


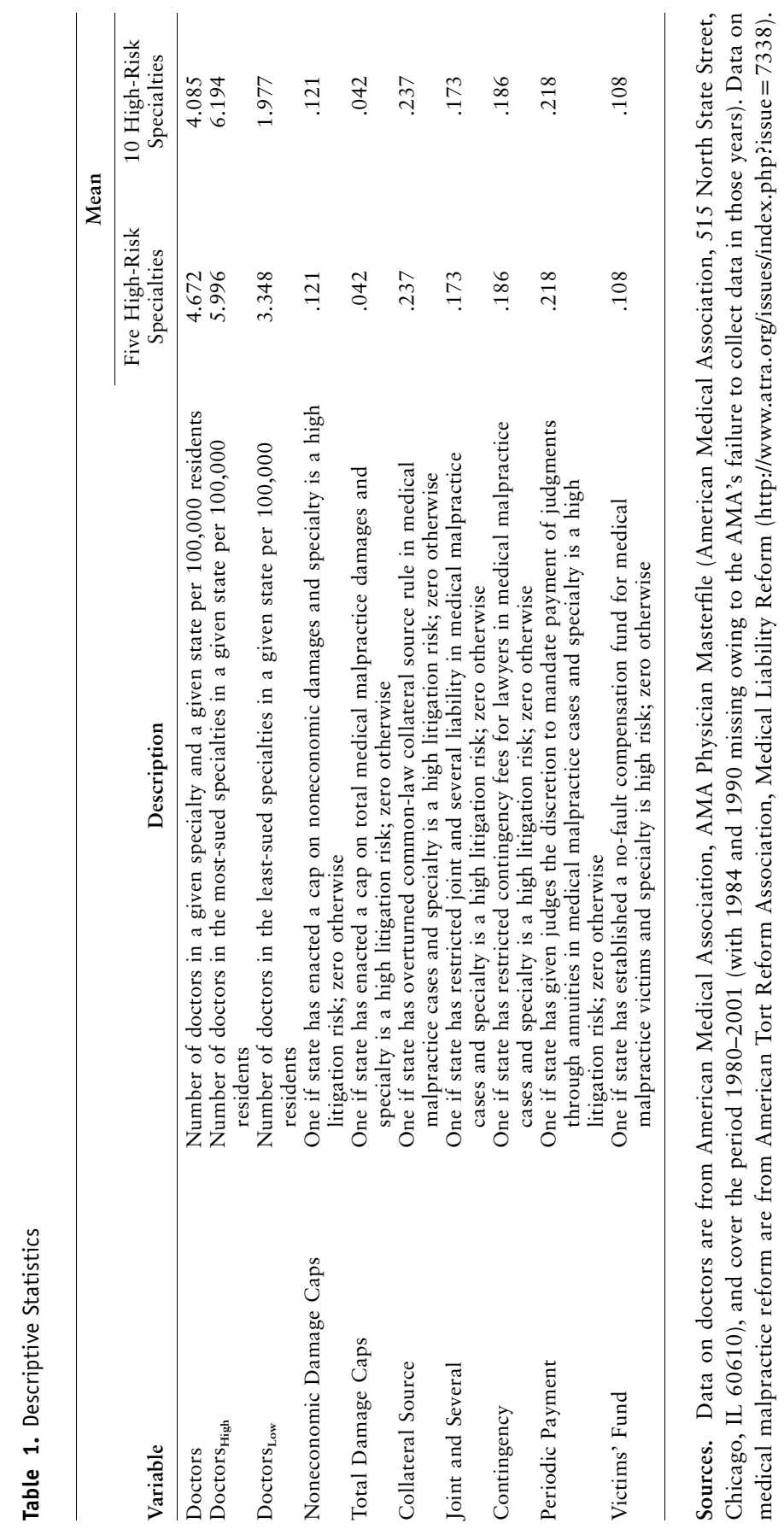


S128 / the JOURnal OF LEgal Studies / VOLUme 36 (2) / JUne 2007

Table 2. Difference-in-Difference Estimator: Medical Malpractice Reforms and the Location of Physicians in High-Risk Specialties

\begin{tabular}{|c|c|c|c|c|}
\hline & \multicolumn{2}{|c|}{$\begin{array}{c}\text { Five Highest-Risk } \\
\text { Specialties }\end{array}$} & \multicolumn{2}{|c|}{$\begin{array}{l}10 \text { Highest-Risk } \\
\text { Specialties }\end{array}$} \\
\hline & (1) & $(2)$ & (3) & $(4)$ \\
\hline \multirow[t]{3}{*}{ Noneconomic Damage Caps } & .029 & .012 & .013 & .008 \\
\hline & $(.011)$ & $(.009)$ & $(.006)$ & $(.005)$ \\
\hline & {$[.034]$} & {$[.013]$} & {$[.025]$} & {$[.008]$} \\
\hline \multirow[t]{3}{*}{ Total Damage Caps } & .005 & .022 & .028 & .027 \\
\hline & $(.022)$ & $(.015)$ & $(.012)$ & $(.008)$ \\
\hline & {$[.057]$} & {$[.011]$} & {$[.044]$} & {$[.006]$} \\
\hline \multirow[t]{3}{*}{ Collateral Source } & .033 & .015 & .027 & .005 \\
\hline & $(.010)$ & $(.009)$ & $(.006)$ & $(.005)$ \\
\hline & {$[.025]$} & {$[.017]$} & {$[.022]$} & [.010] \\
\hline \multirow[t]{3}{*}{ Joint and Several } & -.056 & -.009 & -.045 & -.006 \\
\hline & $(.012)$ & $(.012)$ & $(.007)$ & $(.006)$ \\
\hline & {$[.021]$} & {$[.011]$} & {$[.021]$} & {$[.006]$} \\
\hline \multirow[t]{3}{*}{ Contingency } & -.002 & -.017 & .007 & -.010 \\
\hline & $(.015)$ & $(.012)$ & $(.008)$ & $(.006)$ \\
\hline & {$[.024]$} & {$[.017]$} & {$[.021]$} & [.009] \\
\hline \multirow[t]{3}{*}{ Periodic Payment } & .004 & -.000 & -.008 & -.000 \\
\hline & $(.010)$ & $(.008)$ & $(.006)$ & $(.004)$ \\
\hline & {$[.017]$} & {$[.015]$} & {$[.016]$} & [.009] \\
\hline \multirow{3}{*}{ Victims' Fund } & -.040 & -.006 & -.030 & -.009 \\
\hline & $(.017)$ & $(.014)$ & $(.009)$ & $(.008)$ \\
\hline & {$[.048]$} & {$[.011]$} & {$[.035]$} & {$[.010]$} \\
\hline $\begin{array}{l}\text { State } \times \text { specialty-specific } \\
\text { trends }\end{array}$ & No & Yes & No & Yes \\
\hline Observations & 4,799 & 4,799 & 9,644 & 9,644 \\
\hline Adjusted $R^{2}$ & .988 & .994 & .990 & .996 \\
\hline
\end{tabular}

Note. The dependent variable is the natural log of the number of doctors in a given specialty per 100,000 state residents. Robust standard errors are in parentheses, and standard errors clustered by state are in square brackets. Regressions for the five highest-risk specialties examined the number of doctors in each specialty (per 100,000 state residents) for the following specialties: neurological surgery, thoracic surgery, obstetrics and gynecology, general practice, and emergency room. Regressions for the 10 highest-risk specialties added the following specialties: plastic surgery, radiology, anesthesiology, general surgery, and cardiovascular disease. All regressions were estimated with state population weights and include specialty $\times$ year and state $\times$ specialty effects.

high-risk specialties in Table 2, using the natural log of the number of doctors per 100,000 state residents in each state's specialty group for high-risk specialties only. We find that no reform has a consistently statistically significant effect on doctors' location decisions across specifications, with or without state and specialty-specific trends. However, 
given the potential for endogeneity, these estimated effects are likely to be biased.

For our triple-differences analysis, we examine the natural log of the number of doctors per 100,000 state residents in each state and specialty group for both the high- and low-risk specialties (as described above), using separate year dummies for each specialty $(\tau)$, separate fixed effects for each specialty in each state $(\lambda)$, and separate year dummies for each state $(\varphi)$ to control for any time-varying effects within each state. In addition, in these specifications, the REFORM vector only matches the medical malpractice reforms with the observations for the high-risk specialties in cells with state by year interactions in which the reforms are in place. The regression takes the following form:

$$
\ln \left(\text { Doctors }_{i s t}\right)=\beta \times \operatorname{REFORM}_{i s t}+\tau_{i t}+\lambda_{i s}+\varphi_{s t},
$$

where $i$ is specialty, $s$ is state, and $t$ is year. For the triple-differences analysis, we also present a specification that adds separate linear trends for each state and specialty combination as a robustness check.

All regressions are estimated with the appropriate state population weights. ${ }^{11}$ We present robust standard errors and standard errors clustered by state to mitigate the concerns about serial correlation in difference-in-difference analyses raised by Bertrand, Duflo, and Mullainathan (2004). ${ }^{12}$

\section{RESULTS}

The results from the triple-differences model are presented in Table 3. We find that only noneconomic damage caps have a consistently statistically significant effect on the number of doctors per capita in high-risk specialties who are practicing in a state. When only doctors in the five specialties with the highest litigation exposure are considered, noneconomic damage caps are associated with an increase of 6.6 percent $(p=.000)$ when state and specialty trends are not included and of 6.1 percent $(p=.000)$ when the trends are included. The statistical significance holds when standard errors are clustered at the state level $(p=$

11. The results are mostly unchanged if we use a more complicated weighting scheme that recognizes the fraction each specialty contributes to the overall physician pool on average.

12. The results are also robust to estimating Newey-West standard errors when the lag structure is chosen optimally, as suggested in Stock and Watson (2003). 
Table 3. Triple-Differences Estimator: Medical Malpractice Reforms and the Location of Physicians in High-Risk Specialties

\begin{tabular}{|c|c|c|c|c|}
\hline & \multicolumn{2}{|c|}{$\begin{array}{c}\text { Five Highest-Risk } \\
\text { Specialties }\end{array}$} & \multicolumn{2}{|c|}{$\begin{array}{l}10 \text { Highest-Risk } \\
\text { Specialties }\end{array}$} \\
\hline & (1) & $(2)$ & (3) & (4) \\
\hline \multirow[t]{3}{*}{ Noneconomic Damage Caps } & .066 & .061 & .039 & .041 \\
\hline & $(.016)$ & $(.015)$ & $(.012)$ & $(.011)$ \\
\hline & {$[.031]$} & {$[.023]$} & {$[.026]$} & {$[.013]$} \\
\hline \multirow[t]{3}{*}{ Total Damage Caps } & .016 & .016 & -.007 & .007 \\
\hline & $(.031)$ & $(.031)$ & $(.026)$ & $(.023)$ \\
\hline & {$[.048]$} & {$[.034]$} & {$[.021]$} & {$[.019]$} \\
\hline \multirow[t]{3}{*}{ Collateral Source } & .023 & .017 & .013 & -.016 \\
\hline & $(.014)$ & $(.014)$ & $(.010)$ & $(.010)$ \\
\hline & {$[.023]$} & {$[.026]$} & {$[.018]$} & {$[.014]$} \\
\hline \multirow[t]{3}{*}{ Joint and Several } & -.012 & -.001 & .004 & .012 \\
\hline & $(.013)$ & $(.014)$ & $(.010)$ & $(.008)$ \\
\hline & {$[.026]$} & {$[.026]$} & {$[.024]$} & {$[.014]$} \\
\hline \multirow[t]{3}{*}{ Contingency } & -.014 & -.028 & .008 & -.013 \\
\hline & $(.017)$ & $(.016)$ & $(.013)$ & $(.011)$ \\
\hline & {$[.030]$} & {$[.027]$} & {$[.018]$} & {$[.023]$} \\
\hline \multirow[t]{3}{*}{ Periodic Payment } & -.021 & -.008 & .019 & .012 \\
\hline & $(.014)$ & $(.014)$ & $(.011)$ & $(.010)$ \\
\hline & {$[.023]$} & {$[.023]$} & {$[.016]$} & {$[.014]$} \\
\hline \multirow[t]{3}{*}{ Victims' Fund } & .032 & -.013 & -.017 & -.014 \\
\hline & $(.022)$ & $(.022)$ & $(.015)$ & $(.016)$ \\
\hline & {$[.036]$} & {$[.034]$} & {$[.035]$} & {$[.030]$} \\
\hline $\begin{array}{l}\text { State } \times \text { specialty-specific } \\
\text { trends }\end{array}$ & No & Yes & No & Yes \\
\hline Observations & 9,380 & 9,380 & 18,065 & 18,065 \\
\hline Adjusted $R^{2}$ & .991 & .994 & .992 & .995 \\
\hline
\end{tabular}

Note. The dependent variable is the natural $\log$ of the number of doctors in a given specialty per 100,000 state residents. Robust standard errors are in parentheses, and standard errors clustered by state are in square brackets. Regressions for the five highest-risk specialties examined the number of doctors in each specialty (per 100,000 state residents) for the following specialties: neurological surgery, thoracic surgery, obstetrics and gynecology, general practice, and emergency room. Regressions for the 10 highest-risk specialties added the following specialties: plastic surgery, radiology, anesthesiology, general surgery, and cardiovascular disease. For the within-state control groups, the following low-risk specialties were used in the regressions for the five highest-risk specialties: diabetes, neoplastic diseases, oncology, public health, and psychiatry. For the regressions for the 10 highest-risk specialties, the following additional low-risk specialties were used for the within-state control groups: allergy, rheumatology, physical medicine, dermatology, and nephrology. All regressions were estimated with state population weights and include specialty $\times$ year and state $\times$ specialty effects. 
.039 and .010 , respectively). None of the other reforms has a statistically significant effect, and the joint effect of the other reforms is not statistically significant in any specification.

Interestingly, when we examine the 10 specialties with the greatest liability exposure, the relative effect of the reform is diminished, even though the effect of noneconomic damage caps is still positive and generally statistically significant. When state and specialty trends are not included, noneconomic damage caps are associated with an increase of only 3.9 percent ( $p=.002 ; p=.138$ with clustered standard errors). Including the trends increases the effect to 4.1 percent $(p=.000 ; p=$ .002 with clustered standard errors). These effects are only about 60 percent as large as those estimated for the five specialties with the most liability exposure. This suggests that virtually all of the effect of noneconomic damage caps is concentrated in those five specialties.

Interestingly, if we compare the effects estimated in Table 3 with the Table 2 results, we find that the effect of noneconomic damage caps estimated in the triple-differences model is more than two times as large as that estimated in the difference-in-difference model in every specification, and the difference between the coefficients is statistically significant. This implies that noneconomic damage caps most often may be systematically passed in crisis situations when the number of physicians in high-risk specialties has declined. Note that this underestimate of the effect of noneconomic damage caps in the difference-in-difference model occurs even in the specifications that include linear trends. This finding undercuts the claim in Matsa (2007) that including trend indicators before the caps' passage mitigates the possibility that passage is endogenous to the number of doctors in a state.

In Table 4, we present regressions that drop all the reforms except the noneconomic damage caps. The estimates of the effect of noneconomic damage caps are substantially the same as those generated in the model including all the reforms. This suggests that previous studies that focused solely on noneconomic damage caps did not suffer from a bias resulting from the omission of other reforms. Although this is consistent with Matsa's (2007) results from specifications in which he included a general medical malpractice reform control for the presence of any other reform in the state (and the coefficient of the variable for noneconomic damage caps did not change), the results presented here provide a more general robustness check regarding the claim that failure to control for other reforms does not generate an omitted variables bias in the estimated effect of noneconomic damage caps. Specifically, our Table 3 
Table 4. Triple-Differences Estimator: Noneconomic Damage Caps and the Location of Physicians in High-Risk Specialties

\begin{tabular}{lcccccc}
\hline & \multicolumn{2}{c}{$\begin{array}{c}\text { Five Highest-Risk } \\
\text { Specialties }\end{array}$} & & \multicolumn{2}{c}{$\begin{array}{c}\text { 10 Highest-Risk } \\
\text { Specialties }\end{array}$} \\
\cline { 2 - 3 } & $(1)$ & $(2)$ & & $(3)$ & $(4)$ \\
\hline Noneconomic Damage Caps & .066 & .057 & & .046 & .042 \\
& $(.015)$ & $(.014)$ & & $(.011)$ & $(.010)$ \\
State $\times$ specialty-specific & {$[.028]$} & {$[.021]$} & & {$[.027]$} & {$[.014]$} \\
$\quad$ trends & No & Yes & & No & Yes \\
Observations & 9,380 & 9,380 & & 18,065 & 18,065 \\
Adjusted $R^{2}$ & .991 & .994 & & .992 & .995 \\
\hline
\end{tabular}

Note. The dependent variable is the natural log of the number of doctors in a given specialty per 100,000 state residents. Robust standard errors are in parentheses, and standard errors clustered by state are in square brackets. Regressions for the five highest-risk specialties examined the number of doctors in each specialty (per 100,000 state residents) for the following specialties: neurological surgery, thoracic surgery, obstetrics and gynecology, general practice, and emergency room. Regressions for the 10 highest-risk specialties added the following specialties: plastic surgery, radiology, anesthesiology, general surgery, and cardiovascular disease. For the within-state control groups, the following low-risk specialties were used in the regressions for the five highest-risk specialties: diabetes, neoplastic diseases, oncology, public health, and psychiatry. For the regressions for the 10 highest-risk specialties, the following additional low-risk specialties were used for the within-state control groups: allergy, rheumatology, physical medicine, dermatology, and nephrology. All regressions were estimated with state population weights and include specialty $\times$ year, state $\times$ specialty, and state $\times$ year effects.

results allow the various other reforms to generate effects that have differences in sign and size.

Our results suggest that only caps on noneconomic damages have a robust, positive, and statistically significant effect on the location decisions of physicians in high-risk specialties. Unfortunately, given the nature of the data available to examine this question on a comprehensive scale, we cannot isolate the source of this effect-that is, we are not able to determine whether the effect is due to specialists switching the location of their practice mid-career, beginning their practice in states with more favorable tort regimes, delaying their retirement in states with reforms, or some combination of the three. The AMA data do not allow us to determine the relative contributions of these mechanisms, and we are not aware of any nationally comprehensive state-level data set tracking initial licensing decisions or retirement decisions by specialty. 


\section{DOES IT MATTER?}

The preceding results suggest that noneconomic damage caps are effective in increasing the per capita number of doctors in the highest-risk specialties. In fact, if we borrow a calculation from Kessler, Sage, and Becker (2005), it would take a 22 percent increase in doctors' wages to generate a supply response comparable to the response generated by the passage of a cap on noneconomic damages. ${ }^{13}$ Furthermore, since this result represents only the effect on the extensive (entry/exit) margin, it is likely to be the lower bound of the true total effect of caps, given Helland and Showalter's (2006) results regarding the intensive (hours worked) margin.

However, as argued in Klick and Stratmann (2005), it is not clear that this increase in supply will generate improvements in public health. The health improvements resulting from increased access need to be balanced against any harm that is likely to result from the decrease in the incentive for a doctor to provide optimal care.

To examine this potential trade-off, we investigate the effect of medical malpractice reform on infant mortality rates. This health metric seems particularly appropriate to examine in this context, since obstetricians are often the focus of the medical malpractice reform movement. Infant mortality also is potentially affected by both access to care ${ }^{14}$ and quality of care. ${ }^{15}$

Because of evidence of racial discrepancies in infant mortality rates (Leslie et al. 2003), we examine white and black infant mortality rates separately. We include a host of covariates in addition to medical malpractice reforms. We include controls for personal income per capita in the state, a measure of the percentage of the state population with a secondary education, the percentage of the state population without insurance, per capita governmental transfer payments, medical-specific

13. Kessler, Sage, and Becker (2005) use estimates from Rizzo and Blumenthal (1994) that suggest that a 1 percent increase in physician wages leads to a .3 percent increase in hours worked by a physician.

14. For example, Dubay, Kaestner, and Waidmann (2001) found that decreasing liability costs are associated with improved access to prenatal care, especially among black women. The U.S. Department of Health and Human Services (2006) reports that babies born to women who did not receive prenatal care are three times more likely to exhibit low birth weights and five times more likely to die than are babies born to women who received prenatal care.

15. For example, Papworth and Cartlidge (2005) report that half of all instances of perinatal asphyxia during the period 1994-95 in the United Kingdom were the result of suboptimal care. 
transfer payments, and per capita alcohol sales because of the direct negative effect of drinking on pregnancy and as a general proxy for wellness in a state. We also include the percentage of the state population aged 15-19 years, because young mothers experience more difficult pregnancies (Phipps, Sowers, and DeMonner 2002). We add a measure of the abortion rate to control for the possibility that abortion might be a way to prevent postbirth mortality (see Gruber, Levine, and Staiger 1999). Finally, we include the percentage of the state population that is black for the infant mortality regressions for both the white and black populations, because there is some evidence that areas with large minority populations tend to have poor health care resources (Satel and Klick 2005; Klick and Satel 2006). Descriptive statistics are presented in Table 5 .

We examine infant mortality rates in a standard difference-indifference format including time-invariant state fixed effects and year effects that are common to all states. In some specifications, we include state-specific trends as well. Table 6 presents results from these regressions.

The only medical malpractice reform that has a consistently statistically significant effect on infant mortality is collateral source reform. For black infant mortality rates, collateral source reform is associated with an increase in mortality, regardless of whether state-specific trends are included. The effect represents an increase of between 5 and 7 percent in the black infant mortality rate.

Although this may seem surprising, Baker (2001) suggests that collateral source reform is particularly important in the medical malpractice context, since many cases are not brought by plaintiffs' attorneys if the recovery of medical bills is not possible. The deleterious public health effects of collateral source reform are identified in other research as well (Rubin and Shepherd 2007). If this indeed is the driving factor leading to the collateral-source-reform-induced infant mortality effect that we observe among blacks, then it might be surprising that we do not observe a positive relationship between collateral source reform and physician location, since collateral source reform presumably would make practice in a given state cheaper. However, we do find this effect for only the black infant mortality rate, which implies that the benefits of this reform may be nontrivial for doctors working in low-margin areas. If that is the case, we might not expect to see a large (or precise) effect on the overall number of specialists in a state that passes collateral source reform. 


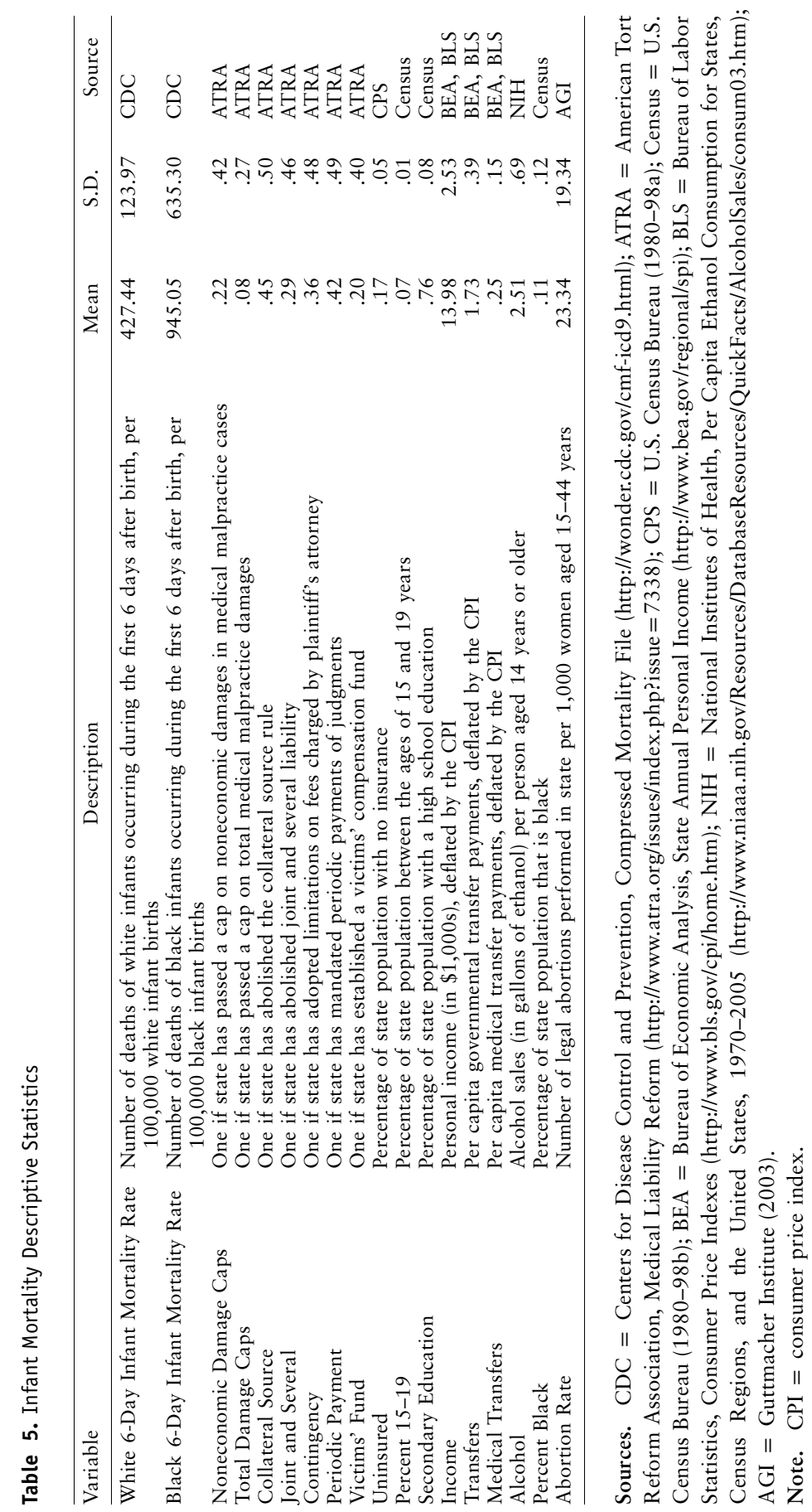


Table 6. Effect of Medical Malpractice Reforms on 6-Day Infant Mortality Rate per 100,000 Births

\begin{tabular}{|c|c|c|c|c|}
\hline & \multicolumn{2}{|c|}{$\begin{array}{l}\text { White Infant } \\
\text { Mortality Rate }\end{array}$} & \multicolumn{2}{|c|}{$\begin{array}{c}\text { Black Infant } \\
\text { Mortality Rate }\end{array}$} \\
\hline & $(2)$ & (3) & $(2)$ & (3) \\
\hline \multicolumn{5}{|l|}{ Noneconomic } \\
\hline \multirow[t]{3}{*}{ Damage Caps } & 5.873 & 2.889 & -55.441 & -5.743 \\
\hline & $(5.269)$ & $(6.374)$ & $(23.309)$ & $(26.236)$ \\
\hline & [5.422] & {$[7.621]$} & [44.443] & [35.306] \\
\hline \multirow[t]{3}{*}{ Total Damage Caps } & 7.948 & -4.634 & 24.018 & -48.308 \\
\hline & $(13.294)$ & $(17.549)$ & $(44.851)$ & $(56.138)$ \\
\hline & [10.437] & [8.927] & [35.684] & [28.436] \\
\hline \multirow[t]{3}{*}{ Collateral Source } & 7.077 & 13.751 & 44.441 & 72.519 \\
\hline & $(5.466)$ & (7.117) & $(19.457)$ & $(25.531)$ \\
\hline & [7.055] & {$[10.970]$} & [21.985] & [32.192] \\
\hline \multirow[t]{3}{*}{ Joint and Several } & 14.018 & 9.425 & 24.480 & 16.581 \\
\hline & $(4.461)$ & $(5.444)$ & $(17.833)$ & $(22.147)$ \\
\hline & [5.458] & [5.934] & [23.304] & [27.668] \\
\hline \multirow[t]{3}{*}{ Contingency } & -11.084 & -13.431 & -68.555 & -18.433 \\
\hline & $(7.310)$ & $(8.310)$ & $(29.301)$ & (31.333) \\
\hline & [7.958] & [11.487] & [29.687] & [26.123] \\
\hline \multirow[t]{3}{*}{ Periodic Payment } & -1.483 & 1.502 & -19.526 & 9.730 \\
\hline & $(6.336)$ & $(7.205)$ & $(25.100)$ & $(31.263)$ \\
\hline & {$[6.236]$} & [7.608] & [23.173] & [30.753] \\
\hline \multirow[t]{3}{*}{ Victims' Fund } & -13.612 & 17.439 & 11.619 & -4.308 \\
\hline & (7.915) & $(13.012)$ & $(25.883)$ & $(38.693)$ \\
\hline & [9.370] & {$[17.737]$} & {$[42.935]$} & [48.015] \\
\hline \multirow[t]{3}{*}{ Uninsured } & -82.405 & -.858 & -44.229 & 151.000 \\
\hline & $(73.759)$ & $(82.939)$ & $(274.372)$ & $(294.669)$ \\
\hline & {$[77.037]$} & {$[97.271]$} & {$[310.084]$} & [383.602] \\
\hline \multirow[t]{3}{*}{ Percent $15-19$} & 223.757 & 232.225 & $5,872.344$ & $5,959.739$ \\
\hline & $(566.490)$ & $(957.377)$ & $(2,740.692)$ & $(3,768.993)$ \\
\hline & {$[728.673]$} & {$[1,180.186]$} & {$[4,136.524]$} & {$[6,283.222]$} \\
\hline \multirow[t]{3}{*}{ Secondary Education } & -438.250 & -17.762 & 575.411 & $1,114.040$ \\
\hline & $(114.950)$ & $(289.203)$ & (492.907) & (885.073) \\
\hline & {$[122.726]$} & [406.437] & {$[653.015]$} & {$[1,170.268]$} \\
\hline \multirow[t]{3}{*}{ Income } & -5.773 & .533 & 27.971 & 21.317 \\
\hline & $(3.447)$ & $(4.143)$ & $(13.475)$ & $(17.067)$ \\
\hline & [4.033] & [4.976] & [17.619] & [24.885] \\
\hline \multirow[t]{3}{*}{ Transfers } & -36.495 & -11.906 & 119.079 & 147.150 \\
\hline & $(26.886)$ & $(42.895)$ & $(104.650)$ & $(179.212)$ \\
\hline & {$[35.922]$} & [49.769] & {$[179.941]$} & [206.337] \\
\hline \multirow[t]{3}{*}{ Medical Transfers } & -65.544 & -66.828 & -391.532 & -129.690 \\
\hline & $(54.134)$ & $(66.759)$ & $(222.229)$ & $(294.290)$ \\
\hline & {$[68.463]$} & [88.804] & [309.039] & [230.405] \\
\hline \multirow[t]{3}{*}{ Alcohol } & 41.226 & 12.346 & -15.909 & 26.323 \\
\hline & $(14.901)$ & $(21.605)$ & $(55.842)$ & $(79.820)$ \\
\hline & [14.640] & [20.852] & [57.164] & [91.491] \\
\hline
\end{tabular}


Table 6. continued

\begin{tabular}{lccccc}
\hline & \multicolumn{2}{c}{$\begin{array}{c}\text { White Infant } \\
\text { Mortality Rate }\end{array}$} & & \multicolumn{2}{c}{$\begin{array}{c}\text { Black Infant } \\
\text { Mortality Rate }\end{array}$} \\
\cline { 2 - 3 } \cline { 5 - 6 } & $(2)$ & $(3)$ & & $(2)$ & $(3)$ \\
\hline Percent Black & 191.301 & 1088.560 & & 500.888 & $5,434.686$ \\
& $(469.984)$ & $(1,063.028)$ & & $(1,483.678)$ & $(2,894.703)$ \\
Abortion Rate & {$[721.435]$} & {$[1,632.726]$} & & {$[2,310.627]$} & {$[2,340.840]$} \\
& -.031 & -.007 & & -2.601 & -1.163 \\
State-specific trends & $(.666)$ & $(.774)$ & & $(2.373)$ & $(2.898)$ \\
Adjusted $R^{2}$ & {$[.889]$} & {$[.979]$} & & {$[2.810]$} & {$[3.642]$} \\
\hline
\end{tabular}

Note: The regressions were estimated with the appropriate population weights and include state and year effects. The dependent variable is the number of infants of each race who died within 6 days of birth, per 100,000 births. Robust standard errors are in parentheses, and standard errors clustered by state are in square brackets. The time period analyzed is 1980-98.

Although the results are not robust across specifications, both noneconomic damage caps and contingency reform appear to improve the black infant mortality rate substantially, although both effects are statistically significant only in the specifications that do not include statespecific trends. Noneconomic damage caps lower the black infant mortality rate by about 6 percent. This may imply that, by attracting doctors to underserved areas, noneconomic damage caps improve access to health care for black mothers. This would be consistent with the findings of Dubay, Kaestner, and Waidmann (2001), who also observed this effect among black mothers. Contingency fee restrictions are associated with a 7 percent reduction in the black infant mortality rate. For the white infant mortality rate, only the abolition of joint and several liability appears to have a statistically significant effect of raising the infant mortality rate, but the effect is small and is not robust to the inclusion of state-specific trends.

Results on accidental deaths provided by Rubin and Shepherd (2007) also are consistent with the notion that, whereas some medical malpractice reforms improve public health, others can prove to be deleterious. Specifically, they found that collateral source reform is associated with an increase in the accidental death rate, whereas most of the other reforms that they examined improve accidental death rates. Although they do not separate medical malpractice reforms from other kinds of tort reforms, it is plausible that most of the effect that they identify 
works through changes in physician labor supply and behavior as a result of medical malpractice reform. ${ }^{16}$

Results by Kessler and McClellan (1996) suggest that medical malpractice reform can lead to a savings in resources, if not necessarily an improvement in public health, because doctors are less likely to engage in defensive medicine when they are shielded from liability. In other words, in a high-liability environment, doctors have the incentive to engage in wasteful testing and procedures that do not improve a patient's health but that do provide cover in the event that litigation arises over a random adverse health event.

The effect of medical malpractice reform on public health is generally an open question that deserves much further research. At a minimum, the results provided here with respect to infant mortality (a health metric that would seem to be most directly related to much of the discussion of medical malpractice reform) suggest that reform in general might not have universally positive or negative effects and that many individual reforms may have no effect at all. However, this conclusion is driven more by a lack of precision in the estimates than by an estimate of the precisely zero effect of reforms, which suggests great value in reexamining this general topic with other health metrics that might allow for more precise estimates of the effects of medical malpractice reforms.

\section{CONCLUSION}

The fear of losing physicians has induced many states to adopt medical malpractice reforms. However, most existing estimates of the relationship between medical malpractice reform and physician labor supply suggest that the effects are modest. Furthermore, there is a concern that the correlation is the result of endogeneity, since the passage of reforms may be related to unobserved factors that also correlate with the size of the physician workforce in a state.

This paper exploits the fact that only physicians in specialties that face high liability exposure are likely to be affected by medical malpractice reforms, while other physicians are likely to be indifferent to

16. Rubin and Shepherd (2007) also suggest that some of the effect arises from improved incentives for consumers to buy safer products when tort reform implicitly lowers the prices of new products. This effect is likely to be more attenuated than the effect of medical malpractice reform, since it will be difficult for national suppliers to enforce differential prices across states given the arbitrage opportunities that this creates for consumers and resellers. 
reforms in their location choice. We estimate a triple-differences model, using physicians in low-risk specialties as a contemporaneous withinstate control group, to net out any time-varying state effects that coincidentally correlate with the adoption of reforms and physician labor supply in a state. We find that the adoption of caps on noneconomic damages has a statistically significant positive effect on the location decisions of doctors in high-risk specialties. This effect is robust and appears to be causal. Furthermore, our results provide greater confidence in a causal interpretation than do studies that treat the passage of reforms as exogenous, as well as studies that do not control for the various kinds of reforms that are passed.

It is not clear what the net effect of increasing the physician labor supply through tort reform is on public health. Improved access is presumed to improve welfare, but there may be offsetting effects as doctors face reduced incentives to provide optimal care when medical malpractice reforms are adopted. We examined the effect of individual medical malpractice reforms on infant mortality and found mixed results for the effect of reform on this public health metric.

If increasing the supply of physicians in high-risk specialties is a goal of policymakers, the results presented here suggest that a targeted approach to medical malpractice reform may be warranted. Specifically, not all the reforms advanced by advocates will increase physician supply. Also, it may be optimal to tailor the reforms so that they apply only to especially sensitive specialties, such as surgery and obstetrics. Previous research also suggests that reforms might best be tailored to apply to only doctors practicing in particularly underserved areas, such as rural counties or minority communities. Broad-based medical malpractice reform that goes beyond noneconomic damage caps and that applies to all physicians regardless of specialty and location, however, will not affect most doctors' supply decisions and could prove deleterious to public health on other margins. 
S140 / the JOURnal OF LEgal Studies / VOLUme 36 (2) / JUNE 2007

\section{APPENDIX}

Table A1. Relationship between High- and Low-Risk Specialties in Three Regression Specifications

\begin{tabular}{lccc}
\hline & $(1)$ & $(2)$ & $(3)$ \\
\hline $\ln \left(\right.$ Doctors $\left._{\text {Low }}\right)$ & .335 & .454 & .167 \\
& $(.006)$ & $(.033)$ & $(.025)$ \\
State effects & {$[.021]$} & {$[.111]$} & {$[.042]$} \\
Year effects & No & Yes & Yes \\
State $\times$ specialty-specific trends & No & Yes & Yes \\
Adjusted $R^{2}$ & No & No & Yes \\
\hline
\end{tabular}

Note. The dependent variable is the natural log of the total number of doctors in high-risk specialties per 100,000 state residents. Robust standard errors are in parentheses, and standard errors clustered by state are in square brackets. The high-riskspecialty variable (Doctors High $_{\text {) }}$ ) is the total number of doctors (per 100,000 state residents) in the following specialties: neurological surgery, thoracic surgery, obstetrics and gynecology, general practice, emergency room, plastic surgery, radiology, anesthesiology, general surgery, and cardiovascular disease. The low-risk-specialty variable (Doctors Low $_{\text {) }}$ is the total number of doctors (per 100,000 state residents) in the following specialties: diabetes, neoplastic diseases, oncology, public health, psychiatry, allergy, rheumatology, physical medicine, dermatology, and nephrology. All regressions were estimated with state population weights. $N=969$ observations.

\section{REFERENCES}

Baicker, Katherine, and Amitabh Chandra. 2004. The Effect of Malpractice Liability on the Delivery of Health Care. Working Paper No. 10709. National Bureau of Economic Research, Cambridge, Mass.

Baker, Tom. 2001. Blood Money, New Money, and the Moral Economy of Tort Law in Action. Law and Society Review 35:275-319.

- 2005. The Medical Malpractice Myth. Chicago: University of Chicago Press.

Bertrand, Marianne, Esther Duflo, and Sendhil Mullainathan. 2004. How Much Should We Trust Differences-in-Differences Estimates? Quarterly Journal of Economics 119:249-75.

Dranove, David, and Anne Gron. 2005. Effects of the Medical Malpractice Crisis on Access to and Incidence of High-Risk Procedures: Evidence from Florida. Health Affairs 24:802-10.

Dubay, Lisa, Robert Kaestner, and Timothy Waidmann. 2001. Medical Malpractice Liability and Its Effect on Prenatal Care Utilization and Infant Health. Journal of Health Economics 20:591-611. 
Encinosa, William, and Fred Hellinger. 2005. Have State Caps on Malpractice Awards Increased the Supply of Physicians? Health Affairs Web exclusive, May 31. http://content.healthaffairs.org/cgi/content/abstract/hlthaff.w5.250.

Gruber, Jonathan, Phillip Levine, and Douglas Staiger. 1999. Abortion Legalization and Child Living Circumstances: Who Is the "Marginal Child"? Quarterly Journal of Economics 114:263-91.

Guttmacher Institute. 2003. State-by-State Trends in Abortion in the United States. http://www.guttmacher.org/presentations/state_ab_pt.html.

Helland, Eric, Jonathan Klick, and Alexander Tabarrok. 2005. Data Watch: Torturing the Data. Journal of Economic Perspectives 19:207-20.

Helland, Eric, and Mark Showalter. 2006. The Impact of Liability on the Physician Labor Market. Working paper. Claremont McKenna College, Claremont, Calif.

Kessler, Daniel, and Mark McClellan. 1996. Do Doctors Practice Defensive Medicine? Quarterly Journal of Economics 111:353-90.

Kessler, Daniel, William Sage, and David Becker. 2005. Impact of Malpractice Reforms on the Supply of Physician Services. Journal of the American Medical Association 293:2618-25.

Klick, Jonathan, and Sally Satel. 2006. The Health Disparities Myth: Diagnosing the Treatment Gap. Washington, D.C.: AEI Press.

Klick, Jonathan, and Thomas Stratmann. 2005. Does Medical Malpractice Reform Help States Retain Physicians and Does It Matter? Working paper. Florida State University College of Law, Tallahassee, Fla. http://papers.ssrn .com/sol3/papers.cfm?abstract_id $=453481$.

Leslie, Jennie, Shelley Galvin, Sandra Diehl, Trude Bennett, and Paul Buescher. 2003. Infant Mortality, Low Birth Weight, and Prematurity among Hispanic, White, and African American Women in North Carolina. American Journal of Obstetrics and Gynecology 188:1238-40.

Matsa, David A. 2007. Does Malpractice Liability Keep the Doctor Away? Evidence from Tort Reform Damage Caps. Journal of Legal Studies 36: S143-S182.

Mello, Michelle, David Studdert, Catherine DesRoches, Jordon Peugh, Kinda Zapert, Troyen Brennan, and William Sage. 2004. Caring for Patients in a Malpractice Crisis: Physician Satisfaction and Quality of Care. Heath Affairs 23:42-53.

- 2005. Effects of a Malpractice Crisis on Specialist Supply and Patient Access to Care. Annals of Surgery 242:621-28.

Papworth, Sue, and Patrick Cartlidge. 2005. Learning from Adverse Eventsthe Role of Confidential Enquiries. Seminars in Fetal and Neonatal Medicine 10:39-43.

Phipps, Maureen, Maryfran Sowers, and Sonya DeMonner. 2002. The Risk for Infant Mortality among Adolescent Childbearing Groups. Journal of Women's Health 11:889-97. 
S142 / the JOURnal OF LEgal Studies / VOLUme 36 (2) / JUNE 2007

Rizzo, John, and David Blumenthal. 1994. Physician Labor Supply: Do Income Effects Matter? Journal of Health Economics 13:433-53.

Rubin, Paul H., and Joanna M. Shepherd. 2007. Tort Reform and Accidental Deaths. Journal of Law and Economics 50:221-38.

Satel, Sally, and Jonathan Klick. 2005. The IOM Report: Too Quick to Diagnose Bias. Perspectives in Biology and Medicine 48:S15-S25.

Stock, James, and Mark Watson. 2003. Introduction to Econometrics. New York: Addison-Wesley.

U.S. Census Bureau. 1980-98a. Current Population Survey. Conducted by the Bureau of the Census for the Bureau of Labor Statistics. Washington, D.C.: U.S. Census Bureau.

1980-98b. Statistical Abstract of the United States. Washington, D.C.: U.S. Department of Commerce.

U.S. Department of Health and Human Services. 2006. Fact Sheet: Preventing Infant Mortality. January 13. http://www.hhs.gov/news/factsheet/infant.html. 